\title{
Carl Schmitt e Baruch de Spinoza - ou as aventuras do conceito do político
}

\author{
Carl Schmitt and Baruch de Spinmoza - \\ Or the concept adventures concerning the politician
}

\author{
Manfred Walther ${ }^{1 *}$
}

\begin{abstract}
Resumo
O presente texto objetiva apresentar o modo de apropriação por Schmitt dos conceitos filosóficos e políticos de Spinoza. Para tanto, buscar-se-á mapear em Schmitt onde tais conceitos emergem e qual sua função na economia da obra de Schmitt. Um segundo momento se assinalará a partir desses mesmos conceitos de Spinoza uma crítica a Schmitt numa reversio argumentativa. Espera-se ao final haver podido iluminar reciprocamente Schmitt e Spinoza.
\end{abstract}

Palavra-chaves: Schmitt, Spinoza, Político, Metafísica.

\begin{abstract}
This paper aims to present the mode of appropriation by Schmitt of philosophical and political concepts of Spinoza. We will go with in the Schmitt's work identify where such concepts emerge and what its role in the economy of the work of Schmitt. Secondly, we will be distinguished from these same concepts of Spinoza a critique of Schmitt in reversio argumentative. It is expected to end, enlighten Schmitt and Spinoza.
\end{abstract}

Key-word: Schmitt, Spinoza, Politics, Metaphysics

Como é por todos sabido, a filosofia política de Spinoza não tem tido um grande impacto na Alemanha; se a considerarmos por comparação à influência de sua metafísica, de sua filosofia da religião e de sua crítica da Bíblia, este aspecto de seu pensamento

\footnotetext{
1 *Manfred Walther é professor Emérito na Leibniz Universität - Juristische Fakultät - Institut für Nationale und transnationale Integrationsoforschung. O presente texto apareceu em Spinoza au XXe siècle, Paris: PUF, 361-374. Trad. de Danilo Vaz-Curado R. M. Costa UNICAP/PE. Agradecemos vivamente ao Prof. Manfred Walther pelo envio do texto e a autorização de sua publicação no presente volume.
} 
é relativamente desconhecido. Ora, contra todas as probabilidades, vemos Spinoza citado muitas vezes por Carl Schmitt - como pensador metafísico e poucas vezes por sua dimensão política -, que lhe consagra, por vezes, longos desenvolvimentos no contexto de seu sistema. É um dado conhecido por todo o meio de especialistas de Carl Schmitt e da pesquisa hobbesiana, no continente, que Hobbes ocupa um lugar central no pensamento de Schmitt. Ao contrário, a função de Spinoza permaneceu até o presente momento largamente ignorada.

Nas reflexões que se farão apresentar, não há a ambição de compensar de um golpe esta lacuna: de fato, o presente trabalho não se baseia sobre o estudo de todos os interessantes documentos de nosso objeto de pesquisa; em lugar disso, e de modo a suprir esta deficiência, se explorado o índex dos nomes próprios nas principais obras de Schmitt, assim como as passagens de sua obra facilmente acessíveis ao leitor; essencialmente, o longo capítulo do Leviatã de 1938. Schmitt retém, ao que me parece, essencialmente, três aspectos de Spinoza:

a) Ele encontra na metafísica de Spinoza uma confirmação de sua tese da analogia estrutural existente entre o pensamento teológico e o pensamento político, portanto, uma confirmação da existência de uma teologia política.

b) Schmitt vê em Spinoza o verdadeiro pioneiro do liberalismo político, a saber, uma corrente do pensamento político que, a traços largos, põe um fim à tese do Estado como lugar de identidade política de um povo.

c) E, por fim, Schmitt vê em Spinoza o verdadeiro inventor da teoria da soberania do povo, concepção que representa o resultado lógico da ideologia democrática triunfante desde o século XIX.

Como Schmitt afirma que há uma incompatibilidade fundamental entre o liberalismo e a democracia, a filosofia de Spinoza funciona mesmo como um pôr à prova de consistência, ou mesmo como uma instância crítica, a todo o pensamento de Schmitt. 
Serão tomados agora alguns importantes textos de Schmitt, em sua ordem cronológica, para localizar as posições que ele atribui a Spinoza, antes de proceder a uma confrontação sistemática das duas teorias do político.

1) Quando aborda Spinoza, Schmitt profere um conjunto de dúvidas acerca da possibilidade de lhe ordenar na categoria do racionalismo, tal como entendida no século XVII. Tal postura, já ocorre na primeira obra que aqui se utilizará, a saber, $O$ romantismo político, que data de $1919^{2 *}$.

Buscando definir as raízes do romantismo na história das ideias ${ }^{3}$, ele estabelece um paralelismo estrutural que envolve o percurso dos anos 1800 e o século XVII. "Os sistemas do idealismo pós-kantiano [...] contêm uma filosofia da intuição e um racionalismo panteísta", é assim que eles se opõem a "um conceito imanentista, que põe a individualidade concreta", "a um racionalismo abstrato, que apenas conhece conceitos abstratos e analíticos - os quais não podem aceder à individualidade concreta"; do mesmo modo, "o sistema de Spinoza é... a primeira reação filosófica - análoga nisto àquela do pós-kantismo - contra o racionalismo abstrato dos tempos modernos, representado à época por Descartes e Hobbes. É uma reação a uma concepção de mundo mecanicista"4. Schmitt põe em paralelo a reação de Spinoza no contexto filosófico da metade do século XVII com os movimentos do pensamento que ele qualifica também de intuicionistas, a saber:

$2^{*} 2^{\mathrm{a}}$ ed., 1925; $3^{\mathrm{a}}$ ed. Inalterada, 1968: é esta última edição que se utiliza para citações.

3 A definição que Schmitt profere acerca do romantismo é essencialmente política: trata-se da atitude estetizante que consiste em evitar a decisão política. Ela se traduz essencialmente na ironia romântica: aqui veremos aparecer à dominante existencial Lebensphilosophisch, do pensamento do primeiro Schmitt.

4 Carl Schmitt, Politische Romantik [Romantismo Político], p. 80.

Ano $13 \cdot$ n. $1 \cdot$ jan./jun. $2013-49$ 
- A mística antifilosófica (Guyon, Antoinette, Bourignon, Fénelon e Poiret) contrariamente à corrente de pensamento imanentista, ela se caracteriza por "uma franca tendência à crítica social". 5

- A corrente histórico-tradicionalista de Vico; e

- A corrente do estetismo e do sentimento: para Schmitt, Shaftesbury como primeiro representante, mas é apenas a partir de Rousseau que ela "se afirma indiscutivelmente". ${ }^{6}$

Não se deve deixar de constatar que essa interpretação de Spinoza é condicionada, entre outros motivos, pela Renaissance spinozista na Alemanha, devido à ação de Jacobi. É de toda forma assinalável que, para Schmitt, Spinoza se diferencia de Hobbes por dois pontos - ele não é mecanicista, e a questão central de sua filosofia é um conceito de individualidade: trata-se nisso, efetivamente, das duas maiores preocupações de Spinoza.

2) Aproximadamente dez anos mais tarde, Schmitt retorna acerca do pensamento de Spinoza, tomando-o enquanto a superação da abstração do racionalismo mecanicista. De maneira surpreendente, essas reflexões intervêm num contexto totalmente outro, aquele em que ele aborda o problema do fundamento da constituição. É a constituição que define o domínio de competência dos órgãos constitucionais instaurados por ela e, portanto, ela não tem o poder de se fundar a si mesma.

Para a Verfassungslehre (Doutrina da Constituição) de 1928, trata-se, portanto de identificar qual é o fundamento da constituição. E, em referência com a questão de saber por quais meios se podem superar o estado de exceção na política, ele coloca novamente o problema em seu livro Die Diktatur ( $2^{\mathrm{a}}$ ed., 1928). Neste contexto, ele comenta a distinção estabelecida por Sieyès entre poder constituinte e poder constituído, em oposição 
a uma doutrina do Estado racionalista, que culmina em Condorcet. Eis como ela a caracteriza: "A teoria de Sieyès, ao contrário, apenas se concebe como a expressão da procura do princípio de organização inorganizável", e de modo desconcertante, ele delimita como:

A idéia de relação entre poder constituinte e poder constituído encontra um correspondente perfeitamente sistemático e metódico na ideia de relação entre natura naturans $e$ natura naturata, e se esta ideia também se encontra no sistema de Spinoza, eis a prova de que este sistema não é apenas um racionalismo. ${ }^{7}$

E Schmitt retoma essa ideia na Doutrina da Constituição na passagem seguinte, onde ele dá uma definição de analogia metafísica: "Um fundamento primeiro inexaurível, de todas as formas, ele mesmo refratário a se deixar apreender numa forma, que gere eternamente novas formas, fundamento sem forma, que dá nascimento a todas as outras formas". ${ }^{8}$

Schmitt assinala aqui uma analogia estrutural entre a doutrina da constituição segundo Sieyès e a metafísica de Spinoza, o que parece exigir várias observações:

$a$ - A interpretação de Spinoza defendida aqui não tem suas raízes no estudo do Tractatus Politicus, que Schmitt aparentemente não conhece. Ele mesmo até vai enxergar um antagonismo de pesadas consequências entre a metafísica de Spinoza e a sua teoria política: aquela, a seus olhos, é influenciada pelo direito natural racionalista, mas também - em todo caso - por Maquiavel. ${ }^{9}$ Ele vê na teoria dos dois poderes uma confirmação de sua tese central, a saber, que "todos os conceitos da teoria moderna

Carl Schmitt, Die Diktatur, p.142.

Carl Schmitt, Verfassungslehre, p. 80.

Carl Schmitt, Politische Romantik, 81, n. 1, trad. "A filosofia do estado segundo Spinoza é fortemente influenciada pelo direito natural de sua época e por Maquiavel por ser a expressão típica e lógica de sua filosofia imanentista”. In Politische Romantik, 81, n. 1.

Ano $13 \cdot$ n. $1 \cdot$ jan./jun. $2013-51$ 
do estado... são conceitos teológicos secularizados". ${ }^{10}$ A teoria do poder legislativo de Sieyès deve absolutamente "ser distinguida desta metafísica panteísta: as duas não se confundem em nada". ${ }^{11}$ Pois, "a metafísica da potestas constituens como analogon da natura naturans faz parte da doutrina da teologia política". ${ }^{12}$

É admirável que numa época cuja pesquisa apenas se interessa superficialmente - e, isto é um eufemismo - pelas implicações da metafísica de Spinoza no domínio da teoria política, Schmitt as tenha claramente formulado, enquanto ele não conhecia a obra de Spinoza que tratava destas questões.

b. Do pensamento de Spinoza Schmitt retém sobretudo o movimento, sempre inacabado em seu princípio, de baixo para cima, isto é, da potência da multidão até às instituições políticas. Ela a diferencia assim claramente daquela de Hobbes - essa perspectiva de Schmitt se distancia daquela que ordinariamente se tem da relação entre Hobbes e Spinoza na história das ideias políticas, caracterizando assim a posição fundamental de Spinoza - que pertence também a Sieyès - enquanto "princípio de organização inorganizável" 13 , Schmitt faz pensar - e aqui isto não é um acaso - na análise dada por Antonio Negri já há alguns anos (in A anomalia selvagem, 1982), disto que ele designava por pensamento selvagem enquanto característica de Spinoza. Conduz assim ao tema, tanto fascinante, quanto esquivo, de Carl Schmitt e a esquerda europeia - e, contra todas as probabilidades, seguindo o fio condutor da interpretação de Spinoza!

c. Enfim, a partir da observação feita por Schmitt da analogia entre a teoria da constituição em Sieyès e a metafísica de Spinoza, é preciso analisar a relação entre Sieyès e Spinoza no prolongamento disto que dizia, em 1906, Pariset a propósito da organização das diversas constituições, e que Vernière se limita a

\footnotetext{
Carl Schmitt, Politische Theologie, $2^{\mathrm{a}}$ ed., 1934, p.49.

Carl Schmitt, Verfassungslehre, p. 80.

Carl Schmitt, Verfassungslehre, p. 80.

Carl Schmitt, Die Diktatur, p.142.

52 - Universidade Católica de Pernambuco
} 
resumir em seu livro de 1954. Antes de tudo, deve-se examinar a questão de uma história da tradição que vai de Spinoza a Sieyès (se bem que deva excluir-se a hipótese de uma leitura direta).

3/ De passagem, faz-se necessário simplesmente mencionar o fato de que Spinoza intervém bem ao início - desta vez, sem que seu nome seja citado - na terceira edição, ulteriormente passada em silêncio por Schmitt, de Der Begriff des Politischen, que data de 1933, isto é, do período imediatamente seguinte à tomada do poder por Hitler. ${ }^{14} \mathrm{Na}$ segunda página, após uma definição do inimigo como o existencialmente outro, estrangeiro, aquele "com quem, no caso extremo, os conflitos existenciais são possíveis", pode-se ler em duas frases mais longas:

Quanto as questões de saber se existe um caso extremo, ou de definir os meios extremos que seriam de uma necessidade vital para defender sua própria existência e conservar seu ser próprio - in suo esse perseverare - nem um, nem outro não poderiam ser definidos por um estrangeiro. ${ }^{15}$

Spinoza não elaborou a filosofia do movimento, e não ensinou que toda a determinação (do próprio ser) é ao mesmo tempo uma negação, exclusão (do estrangeiro), que cada um tem tanto o direito de conservar no seu ser o que ele tem na sua potência? A referência cínica de Schmitt ao conceito central de Spinoza não toma assim uma conotação (não tem também, portanto, ela um pano de fundo) teórica à qual se deve tomar em consideração?

4/ É num contexto totalmente diverso, à primeira vista, que Schmitt fala de Spinoza, na obra, onde, segundo sua própria análise, ele começa a tomar claramente sua distância em face do Estado Nacional Socialista. Lá ele se refere a Hobbes para de-

\footnotetext{
14 Agradeço a Manfred Lauermann de haver assinalado este texto. Acerca deste ponto, Cf., Lauermann/Heerich, 1991.

15 Carl Schmitt, Der Begriff des Politischen, p. 8.
} 
signar uma instância representativa, realizada pelo princípio da autoridade superior, enquanto "Deus mortal"; Leviatã, também representa justamente o Deus imortal, enquanto este homem artificial que tem o aspecto de uma máquina, orientada na direção da época futura, aquela de uma "neutralização e da despolitização" aquela na qual o agir saído do político representando o absoluto - isto é, a autoridade de distinguir o amigo do inimigo - dá lugar a um puro formalismo na resolução dos conflitos de interesse, numa sociedade pluralista e dividida, organizada em lobbies.

O mesmo equívoco que se traduz na imagem dupla do Leviatã definido como grande máquina, de um lado, e Deus mortal de outro, se encontra novamente na relação entre a autoridade do Estado e a interioridade da consciência - quer ela verse acerca da liberdade de religião ou do pensamento livre: certamente, Hobbes faz da prática exterior da religião no culto, dos dogmas oficiais e da questão de saber quais milagres são objetos da crença oficial, um negócio de Estado; mas, ele reserva o espaço interior da subjetividade, a qual, nele se dá desde uma definição religiosa ou filosófica, e Schmitt insiste acerca deste ponto, por agnosticismo religioso.

Assim, encontra-se estabelecida uma relação com a teologia política, pois é justamente este agnosticismo que conduz necessariamente, em virtude de sua emancipação da teologia, a este processo de enfraquecimento da autoridade do Estado que o tempo apresenta repentinamente suas consequências.

Eis em que consiste este encadeamento inelutável, segundo Schmitt

A distinção entre privado e público, a fé e a confissão, fides e confessio, faith e confession... foi introduzida de tal modo que, no curso do século seguinte até o Estado liberal, o Estado de Direito, o Estado constitucional, tudo se encadeia logicamente a partir daí. ${ }^{16}$

16 Carl Schmitt, Leviathan, p. 85.

54 - Universidade Católica de Pernambuco 
Certamente, Hobbes mantém, decididamente, o primado disto que é público, disto que condiz com o Estado, sobre a esfera privada, da interioridade, mas a brecha está aberta.

"Alguns anos logo após o aparecimento do Leviatã, o olhar do primeiro judeu liberal cai sobre a fenda quase indiscernível. Ele reconheceu, antes de todos, a larga brecha pela qual iria se destruir o liberalismo moderno" ${ }^{17}$. E é seguramente acerca de Spinoza que ele se reporta, Spinoza que faz crer "justamente em sua plena expansão" 18 o "germe da morte que... destruiu do interior o potente Leviatã" ${ }^{19}$, alargando o enclave da interioridade do homem, inacessível à autoridade do Estado "até fazê-lo princípio geral da liberdade de pensar, de sentir e exprimir sua opinião"20. Esses são os termos empregados por Schmitt em sua análise dos capítulos 19 e 20 do TTP ${ }^{21 *}$.

Há aqui, segundo Hobbes, o estatuto de uma exceção, do fato que, segundo Schmitt, ele permanece "na fé de seu povo", tornando-se, assim, "o princípio formador", oposto ao "direito de força do estado soberano", concebido como puramente restritivo. "Uma ínfima conversão do espírito resultante da existência judia" 22 , torna-se o ponto de partida de um empreendimento visando a minar a autoridade do Estado, a qual Schmitt enumera os vetores:

As alianças e as ordens secretas, os Rosa-Cruzes, os Franco-Maçons, os Iluminatis, os místicos, os Pietistas, os sectários de toda ordem, a maioria silenciosa e, sobretudo, o espírito inquieto judio que tem sabido tirar o melhor partido desta situação. ${ }^{23}$

Por exemplo, Mendelssohn

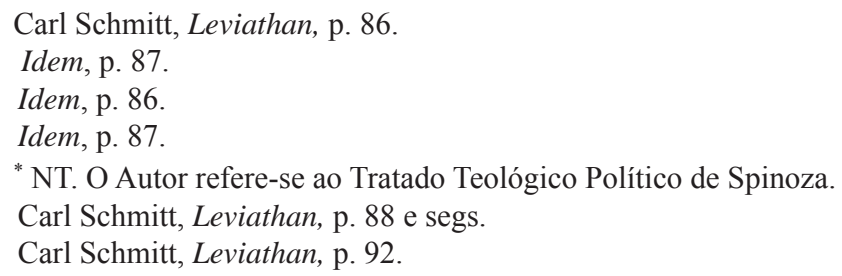


Sem grande espírito, sua inteligência não toleraria a comparação com Spinoza, mas com um instinto infalível, ele pressentia que minar a potência do Estado, esvaziar sua substância, era o melhor meio de paralisar o povo estrangeiro, e de servir a emancipação de seu povo, os judeus. ${ }^{24}$

Esta polêmica veemente contra Spinoza é destinada a dissimular segundo Schmitt a tentação de voltar ao encontro num espaço interior análogo. Em testemunho, uma frase que nós encontramos algumas páginas adiante, e cujo efeito vagamente místico era, sem dúvidas, esperado por Schmitt

\begin{abstract}
Mas, se verdadeiramente o poder do Estado somente quer ser mais que público [....] então, a alma de um povo se engaja sobre o caminho secreto que conduz face a interioridade. É então que crê no retorno da força de se calar e de fazer silêncio. ${ }^{25}$ (Léviathan, p.94)
\end{abstract}

Schmitt emprega aqui os acentos mais eloquentes. Isso significa que o antagonismo entre exterior e interior, já presente em germe em Hobbes, é inelutável na concepção de Schmitt, isto é, que toda a tentativa de restaurar a autoridade do Estado em sua potência original como representante de Deus está devotada ao fracasso? Ou mesmo, apenas faz pôr uma baliza para os pioneiros de épocas futuras, que não poderiam ignorar que Schmitt tem aqui o propósito de se esconder por trás de Spinoza e ou Hobbes - até que o Estado autoritário tenha reduzido uma vez ainda o pluralismo dos diversos lobbies, isto é, até o tempo futuro consoante o fim do estado nazista, o qual exacerbou, em vez de suprimir, como Schmitt havia esperado o pluralismo dos diversos grupos de influência na sociedade?

\title{
III
}

Não se deve deixar de assinalar que Spinoza, tal como aparece a Schmitt, se apresenta sob um duplo aspecto: metafisi-

24 Carl Schmitt, Leviathan, p. 92 e segs.

25 Carl Schmitt, Leviathan, p. 94.

56 - Universidade Católica de Pernambuco 
camente e filosoficamente, ele é o primeiro adversário da época do racionalismo abstrato, instrumental e mecânico, da época das despolitizações e neutralizações ${ }^{26}$ a ter elaborado filosoficamente o conceito de individualidade concreta e de energia inesgotável do fundamento da existência, até delinear o primeiro esboço conceitual de uma concepção radicalmente democrática da soberania do povo.

Ao mesmo tempo, ele é o primeiro liberal em política a ter proclamado a autonomia do espaço interior da subjetividade, a qual encontra sua manifestação no plano social mediante a liberdade de opinião, etc., introduzindo assim, senão o fim, pelo menos a crise do Estado enquanto representante terrestre do absoluto, crise que se estende até os nossos dias.

Em termos de ciência política: se, como lhe diz Schmitt, o antagonismo entre a democracia e o liberalismo somente permaneceria oculto por longo tempo se os dois fossem aliados contra o Estado monárquico feudal, como dois aspectos de emancipação burguesa, isto é, social, face a face do Estado, e se, uma vez alcançada a vitória definitiva sobre o inimigo político, seu conflito deveria inevitavelmente rebentar ao fim, como antagonismo entre o princípio da democracia no sentido rousseauísta (princípio da comunidade formando um todo homogêneo) e o princípio do liberalismo (o princípio de uma sociedade individualista e pluralista) - se, portanto, este antagonismo se enraíza na lógica destes dois princípios de organização política da sociedade, então somente se pode estar desconcertado ao ver que, segundo Schmitt, Spinoza é convocado como o iniciador e testemunha maior das duas evoluções. Dito em outros termos: a ele deve ser possível denotar a falha no pensamento mesmo de Spinoza, a linha de fratura, o tormento dissimulado, que estabelece a separação entre os

Este é o título de um ensaio de Schmitt de 1929, publicado pela primeira vez em Positionen und Begriff im Kampf mit Weimar-Genf-Versailles, 1923-1939, 1940, p.120-132, e republicado na re-edição em 1963, de Der Begriff des Politischen 9segundo a $2^{\text {a }}$ edição de 1932), p. 79-95.

Ano $13 \cdot$ n. $1 \cdot$ jan./jun. $2013-57$ 
dois domínios.

Retornemos à fórmula: se pudermos mostrar que, segundo Spinoza, os elementos das duas formas de organização política da sociedade erigem-se de uma aproximação única, e há uma ligação entre eles, se teria aí um fio sólido ao qual se poderia reconstruir um crítica sistemática ao pensamento de Schmitt, sem se afundar nos paradoxos do manuseio dos conceitos aos quais Schmitt, era, parece-nos, bem superior à maior parte de seus adversários.

Passa-se agora, a esboçar a maneira na qual se desenvolve a relação intrínseca entre os componentes democráticos e os componentes liberais segundo Spinoza, na medida em que este tema transborda largamente o escopo do qual se partiu e se pretende desenvolver no presente texto:

1/ Spinoza não acredita que um povo ou nação possam governar-se a si mesmo perfeitamente, sem um soberano. Isto suporia em efeito que todos os homens se guiem pela razão para viver - e, é justamente a utopia que ele propõe desmascarar. Assim, ele exclui de imediato toda forma de rousseauísmo, à medida a que ele põe como condição constitutiva do Estado a homogeneidade essencial de um povo, se nós não quisermos cair numa ditadura da virtude. ${ }^{27}$

2/ Mas, de outra parte, o liberalismo de Spinoza tem limites: o pensamento e a ação humanas estando sob a dominação permanente das paixões faz resultar que se continuará a manipular as massas lhes fazendo aderir às ideologias coletivas, a função de integração social e política (de onde emerge igualmente suas reflexões acerca de uma religio civilis) - de todo modo, as passagens onde se exprime sua teoria da revolução, sobretudo, mostram que ele tem consciência da impossibilidade fundamental de colocar um freio autoritário à "espontaneidade" dos cidadãos.

Schmitt pensa que o jacobinismo é a conseqüência direta da doutrina rousseauísta da vontade geral.

58 - Universidade Católica de Pernambuco 
3/ Segundo Spinoza, "a união da potência de todos" ameaça enquanto caso limite de poder político, toda a forma de dominação particular, em qualquer sorte de interior ou desde baixo - é nisto em que consiste o fundamento democrático inalienável de toda a forma de governo.

A espontaneidade dos cidadãos, isto é, o desejo de viver segundo sua própria compleição - mas, também, de ver todos os outros se conformarem a esta compleição que é a minha particular - provoca reações hostis à ação do Estado. Essa polaridade ambivalente entre liberdade e dominação, tendências coletivistas e individualistas, apenas produz sua plena eficácia segundo Spinoza no sentido de uma argumentação da potência da afirmação de todos, quando num processo de determinação recíproca do Estado e dos cidadãos a argumentação da potência de agir do Estado vai de acordo com o aumento da liberdade dos cidadãos - por redistribuição de uma potência de agir maximal aos cidadãos, sob a forma de direitos subjetivos individuais - assegurando constitucionalmente a soberania do povo.

Este equilíbrio instável entre poder estatal e liberdade do cidadão não é uma democracia identitária, nem um puro liberalismo; ele está à mercê das crises, e o risco de regressão existe. Mas, não há alternativa a este modelo estrutural interativo de progressivo aumento do poder do Estado e da liberdade do cidadão.

A oposição entre democracia e liberalismo visualizada desde este ponto de vista, não seria suficientemente realista, ela seria antes de tudo uma utopia abstrata - o que, naturalmente, valeria a fortiori para todas as tentativas de continuar independentemente a jogar com o antagonismo desses dois modelos.

Como fazer a crítica de Spinoza, partindo de Schmitt e do ponto de vista da teoria política atual? A questão merece ser debatida. O tema Carl Schmitt e Baruch de Spinoza parece mais rico, em todo o caso, do que se mostrava inicialmente. 


\section{Bibliografia}

SCHMITT, Carl. Politische Romantik. Munich, Duncker und Humblot, 1919 (2a ed., 1925; 3a ed. (aumentada), 1968).

. Politische Theologie. Vier Kapitel zur Lehre von der Souveränität. Munich, Duncker und Humblot, 1922. (2a ed., 1934)

. Die Diktatur. Von den Anfängen des modernen Souveränitätsgedankens bis zum proletarischen Klassenkampf. Munich, Duncker und Humblot, 1921 (2a ed., 1928; 3a ed., 1964).

. Der Begriff des Politischen. Berlin-Grunewald, 1921 (2a ed. 1932; 3a ed., Hanseatische Verlagsanstal, 1938).

. Verfassungslehre. Munich, Duncker und Humblot, 1928 (5a $\overline{\text { ed., 1970). }}$

. Der Leviathan in der Staatslehre des Thomas Hobbes. Hamburg: Hanseatische Verlagsanstalt, 1938 (nova edição e paginação com anexo e posfácio de G. Maschke, Colônia, 1982.

. Positionen und Begriffe im Kampf mit Weimar - Genf - Versailles. Hamburg: Hanseatische Verlagsanstalt, 1940.

LAUERMANN Manfred, Heerich Thomas, Der Gegensatz HobbesSpinoza bei Carl Schmitt (1938), Studia Spinozana, 7, (1991)

NEGRI, Antonio. L'anomalia sauvage: Puissance et pouvoir chez Spinoza. Paris : PUF, 1982.

PARISET, G. Sieyès et Spinoza, in Revue de Synthèse Historique, 12 (1906), p. 309-320.

VERNIÈRE, Paul. Spinoza et la pensée française avant la Revolution. Paris : PUF, 1954, 2 vol, 1982. 